\title{
EFEITO DE DIFERENTES TIPOS DE FIBRAS SOBRE FRAÇÕES LIPÍDICAS DO SANGUE E FÍGADO DE RATOS WISTAR
}

\author{
Effect of different types of fibers on the lipid portions of wistar rat blood and liver \\ Moacir Robson Eufrásio', Maria de Fátima Piccolo Barcelos ${ }^{2}$, Raimundo Vicente de Sousa ${ }^{3}$, \\ Wilson César de Abreu ${ }^{4}$, Maria Aparecida Correa Lima ${ }^{5}$, Michel Cardoso de Angelis Pereira ${ }^{6}$
}

\begin{abstract}
RESUMO
Conduziu-se o presente estudo, com o objetivo de avaliar o efeito de diferentes tipos de fibras sobre as fraçoes lipídicas do sangue e fígado de ratos. Para determinar o efeito da pectina citrica, goma guar e celulose sobre o perfil lipidico dos ratos utilizaramse 36 ratos machos da linhagem wistar. Os ratos foram distribuidos aleatoreamente em seis grupos. Cada gruopo foi submetido a uma dieta por 58 dias. As dietas utilizadas foram: A- 10\% de pectina, B - 15\% de pectina, C-10\% de goma guar, D- 15\% de goma guar, $\mathrm{E}-5 \%$ de Celulose sem colesterol e $\mathrm{F}-5 \%$ celulose com $1 \%$ de colesterol. A pectina e a goma guar evitaram o aumento do colesterol total e LDL-c sérico observado na dieta $\mathrm{F}(\mathrm{p}<0,05)$. Não houve diferença significativa entre os tipos de fibras e a quantidades utilizadas. Os níveis séricos HDL-c, VLDL-c e TAG permaneceram inalterados em todos os tratamentos. Os resultados mostram o potencial efeito benéfico da ingestão das fibras solúveis pectina e goma guar no controle da colesterolemia.
\end{abstract}

Termos para indexação: Fibra alimentar, pectina, goma guar, hipercolesterolemia, sangue, fígado, rato.

\section{ABSTRACT}

The present study was designed to evaluate the effect of different types of fibers on lipid portions of mice blood and liver. To determine the effect of citric pectin, guar gum and cellulose on the rat lipid profile, 36 male mice of the Wistar strain were utilized. The mice were allocated randomly into six groups. Each group was submitted to an experimental diet for 58 days. The utilized diets were: A- 10\% pectin, B - 15\% pectin, $\mathrm{C}-10 \%$ guar gum, D- 15\% guar gum, $\mathrm{E}-5 \%$ cellulose with no cholesterol and $\mathrm{F}-5 \%$ cellulose with $1 \%$ cholesterol. Pectin and guar gum prevented the increase of total cholesterol and serum LDL-c found in $\operatorname{diet} \mathrm{F}$ ( $\mathrm{p}<0.05$ ). There was no significant difference among the types of soluble fibers and the amounts utilized. The serum levels HDL-c, VLDL-c, and TAG did not alter in all the treatments. The results show the potential beneficial effect of the ingestion of the soluble fibers pectin and guar gum in cholesterolemia control.

Index terms: Food fiber, pectin, guar gum, hypercholesterolemy, blood, liver, rat.

(Recebido em 12 de setembro de 2008 e aprovado em 12 de janeiro de 2009)

\section{INTRODUÇÃO}

A fibra alimentar corresponde a várias substâncias vegetais que resistem à digestão pelas ennzimas do trato digestório humano. São divididas em fibras solúveis e insolúveis, as fibras solúveis (pectinas, gomas, mucilagens, beta-glucanas, psillium e algumas hemiceluloses), formam géis na presença de água e as fibras insolúveis (celulose, algumas hemiceluloses e lignina), formam misturas de baixa viscosidade. As principais fontes de fibras alimentares são os cereais integrais, leguminosas, frutas e hortaliças (Browm et al., 1999; Buckeridge \& Tiné, 2001; Lairon et al., 2005).

$\mathrm{Na}$ dieta humana a fibra foi considerada, por muito tempo, a porção inerte do alimento, entretanto, nas últimas décadas o interesse nas fibras alimentares aumentou consideravelmente por profissionais das áreas de nutrição e saúde e pela indústria de alimentos (Mattos \& Martins, 2000). Atualmente, são atribuídos à fração fibra dos alimentos diversos efeitos fisiológicos que incluem a regularização do trânsito intestinal, controle glicêmico, redução de câncer de cólon e diverticulites e redução do colesterol sérico (Browm et al., 1999; Weickert \& Pfeiffer, 2008).

As doenças cardiovasculares constituem a principal causa de morte na maioria dos países do ocidente (Lairon et al., 2005). Estudos epidemiológicos mostram uma relação inversa entre o consumo de fibras e o risco de doenças cardiovasculares (Cara et al., 1992; Wu et al., 2003; Londero et al., 2008). O aumento do colesterol total, especialmente da fração LDL-c constitui um importante fator de risco para doenças cardiovasculares, sendo que a inclusão de fibras

\footnotetext{
${ }^{1}$ Médico Veterinário - Instituto Mineiro de Agropecuária/ IMA - Belo Vale, MG

${ }^{2}$ Professora do Departamento de Ciência dos Alimentos/DCA - Universidade Federal de Lavras/UFLA - Lavras, MG - piccolob@ufla.br ${ }^{3}$ Pós-Doctor - UMR-SENAH-INRA - Saint Gilles, France

${ }^{4}$ Doutorando em Ciência dos Alimentos - Universidade Federal de Lavras/UFLA - Lavras, MG - wilsonprofessor@oi.com.br

${ }^{5}$ Bióloga - Universidade Federal de Lavras/UFLA - Lavras, MG - maclima@ufla.br

${ }^{6}$ Doutor em Ciência dos Alimentos, Prof. Adjunto I - Departamento de Ciência dos Alimentos/DCA - Universidade Federal de Lavras/UFLA deangelis25@hotmail.com
} 
solúveis na dieta tem se mostrado uma prática importante no controle efetivo dos níveis do colesterol (Fietz \& Salgado, 1999).

As fibras solúveis e insolúveis têm apresentado, quando ingeridas, efeitos fisiológicos diferenciados (Potty, 1996). O efeito hipocoleterolêmico das fibras é atribuido à sua fração solúvel, porém, a taxa de redução do colesterol pode variar com o tipo e a quantidade de fibra solúvel consumida (Bell et al., 1990; Kris-Etherton et al., 1988).

Alguns mecanismos são propostos para explicar a ação das fibras solúveis na redução dos níveis de colesterol sérico e um deles é baseado na propriedade das fibras solúveis em hidratar-se no meio aquoso do intestino delgado, formando géis caracterizados por ligações cruzadas com os sais biliares, reduzindo o colesterol sérico, uma vez que o colesterol é usado para o reabastecimento de sais biliares no organismo (Judd \& Truswell, 1982; Eastwood, 1992; Melo et al., 2007).

Neste trabalho, objetivou-se verificar os efeitos de diferentes concentrações e tipos fibras dietéticas (fibras solúveis e insolúveis) adicionadas em dietas colesterolemizadas sobre as frações lipídicas do sangue e fígado de ratos.

\section{MATERIAL E MÉTODOS}

Este trabalho foi realizado nos Departamentos de Ciência dos Alimentos e Medicina Veterinária (ensaio in vivo), da Universidade Federal de Lavras, MG.
Foram adicionadas em dietas experimentais contendo colesterol, três tipos de fibras alimentares isoladas em diferentes concentrações, sendo dois tipos de fibras solúveis (pectina e goma guar) e um tipo de fibra insolúvel (celulose).

\section{Ensaio in vivo}

Foram utilizados 36 ratos albinos (Rattus novergicus) machos da linhagem Wistar, com 32 dias de vida e pesando em torno de $85 \mathrm{~g}$, provenientes da Universidade Federal de Alfenas - UNIFENAS, Alfenas, MG.

Durante o experimento, os animais foram mantidos em temperatura ambiente $\left(24^{\circ} \mathrm{C}\right.$ a $\left.28^{\circ} \mathrm{C}\right)$, com períodos alternados de claro-escuro de 12 horas, com acesso à ração comercial padrão e água ad libtum. Após a adaptação de cinco dias, em dieta padrão preparadas com base nas recomendações do AOAC (1990), os animais foram pesados e distribuídos aleatoriamente em gaiolas individuais, nas quais permaneceram por 58 dias. Os animais foram pesados semanalmente e o consumo da dieta foi calculado de três em três dias, pela diferença de peso entre a quantidade oferecida, as sobras e as perdas. Os tratamentos, consistiam de dietas preparadas para conterem $1 \%$ de colesterol e diferentes fontes de fibras, em duas concentrações (10\% e 15\%), e duas dietas controle; uma sem colesterol e a outra com $1 \%$ de colesterol, ambas com 5\% de celulose, apresentadas na Tabela 1.

Tabela 1 - Composição das seis dietas experimentais $(\mathrm{g} / \mathrm{kg})$ identificadas com base no tipo e quantidade de fibra.

\begin{tabular}{ccccccc}
\hline \multirow{2}{*}{ Ingredientes } & \multicolumn{5}{c}{ Dietas* $(\mathrm{g} / \mathrm{kg})$} \\
\cline { 2 - 7 } & $\mathrm{A}$ & $\mathrm{B}$ & $\mathrm{C}$ & $\mathrm{D}$ & $\mathrm{E}$ & $\mathrm{F}$ \\
\hline Amido de milho & 469,48 & 419,48 & 469,48 & 419,48 & 529,48 & 519,48 \\
Caseína & 200,00 & 200,00 & 200,00 & 200,00 & 200,00 & 200,00 \\
Sacarose & 100,00 & 100,00 & 100,00 & 100,00 & 100,00 & 100,00 \\
Óleo de soja & 70,00 & 70,00 & 70,00 & 70,00 & 70,00 & 70,00 \\
Colesterol & 10,00 & 10,00 & 10,00 & 10,00 & - & 10,00 \\
Celulose** & - & - & - & - & 50,00 & 50,00 \\
Pectina** & 100,00 & 150,00 & - & - & - & - \\
Goma-guar** & - & - & 100 & 150 & - & - \\
Pré-mix mineral & 35,00 & 35,00 & 35,00 & 35,00 & 35,00 & 35,00 \\
Pré-mix vitamíni. & 10,00 & 10,00 & 10,00 & 10,00 & 10,00 & 10,00 \\
L-Cistina & 3,00 & 3,00 & 3,00 & 3,00 & 3,00 & 3,00 \\
Bitartarato colina & 2,50 & 2,50 & 2,50 & 2,50 & 2,50 & 2,50 \\
TBHQ & 0,014 & 0,014 & 0,014 & 0,014 & 0,014 & 0,014 \\
\hline Total & 1000 & 1000 & 1000 & 1000 & 1000 & 1000 \\
\hline
\end{tabular}

*Dietas: $\mathbf{A}=10 \%$ de pectina e $1 \%$ colesterol; $\mathbf{B}=15 \%$ de pectina e $1 \%$ colesterol; $\mathbf{C}=10 \%$ de goma guar e $1 \%$ colesterol; $\mathbf{D}=15 \%$ de goma guar e $1 \%$ de colesterol; $\mathbf{E}=$ controle com $5 \%$ celulose e sem colesterol; $\mathbf{F}=$ controle com $5 \%$ de celulose e $1 \%$ colesterol. **Essa quantidade adicionada na dieta trata-se do material comercial com alta $\%$ de pureza. 
Após o período experimental de 58 dias, os ratos foram submetidos a 12 horas de jejum e, em seguida, anestesiados e eutanasiados com éter etílico, de acordo com os procedimentos e princípios éticos da resolução $\mathrm{N}^{\circ}$ 714 do Conselho Federal de Medicina Veterinária-CFMV (2002). O sangue foi colhido, por meio de punção dos grandes vasos abdominais, centrifugado durante cinco minutos, a $3.000 \mathrm{rpm}$, para a separação do soro. O soro foi conservado em gelo, para realização das análises químicas. $\mathrm{O}$ fígado de cada animal foi retirado, pesado e colocado em estufa de ventilação forçada a $60 \pm 5^{\circ} \mathrm{C}$, durante 72 horas, para posteriores análises químicas e bioquímicas.

\section{Análises bioquímicas no soro}

\section{Determinação de frações lipídicas do sangue dos animais}

A determinação do colesterol total foi realizada de acordo com a metodologia proposta por Allain et al. (1974), utilizando-se o kit enzimático colorimétrico, marca In Vitro Diagnóstica $^{\circledR}$ (CAT 10017). A lipoproteína de alta densidade (HDL-c) foi determinada com o sistema de precipitação de proteínas, utilizando o kit enzimático marca In Vitro Diagnóstica ${ }^{\circledR}$ (CAT 044). A concentraççao de triacilgliceróis no soro sanguíneo dos animais foi realizada, utilizando-se o kit enzimático colorimétrico, marca In Vitro Diagnóstica ${ }^{\circledR}$ (CAT 10724) (Fossate \& Principe, 1982). As leituras da absorbância foram realizadas em espectrofotômetro ProCary / 50 a $500 \mathrm{~nm}$. As lipoproteínas de baixa densidade (LDL-c) e as lipoproteínas de muito baixa densidade (VLDLc) foram determinadas de forma indireta conforme Friedewald (1972). Foram utilizadas as seguintes expressões: LDL colesterol $=$ Colesterol total - HDL triacilgligerol $/ 5$ e VLDL $=$ triacilglicerol $/ 5$.

\section{Análises químicas e bioquímicas no fígado}

Para determinar a porcentagem de lipídios totais no fígado dos animais experimentais foi utilizada a metodologia proposta pela AOAC (1990). Os fígados dos animais experimentais, foram finamente triturados e desengordurados em cartucho de celulose (cerca de $3 \mathrm{~g}$ da amostra seca), em aparelho de Soxhlet, usando éter etílico como solvente. Os cálculos foram feitos em base de matéria seca.

\section{Determinação do colesterol total e triacilgliceróis}

Foi utilizado o método de extração proposto por Folch et al. (1957) para a extração do colesterol e triacilgliceróis hepáticos. Nesse método, $100 \mathrm{mg}$ de fígado, foram triturados em politron, durante 3 minutos, com 1900 $\mu \mathrm{L}$ de solução clorofórmio-metanol 2:1. Depois deste procedimento, foram adicionados $400 \mu \mathrm{L}$ de metanol ao material triturado. Esse material foi então centrifugado a $3.000 \mathrm{rpm}$, durante dez minutos. O sobrenadante foi transferido para outro tubo e adicionado de $800 \mu \mathrm{L}$ de clorofórmio e $640 \mu \mathrm{L}$ de solução de $\mathrm{NaCl}$ a $0,73 \%$. Após este procedimento, houve nova centrifugação a $3.000 \mathrm{rpm}$, durante dez minutos. Desta vez, descartou-se o sobrenadante e o precipitado foi lavado por três vezes com a solução de Folch (3\% de clorofórmio, $48 \%$ de metanol, $47 \%$ de água e $2 \%$ de $\mathrm{NaCl}$ a $0,2 \%$ ). Os extratos lipídicos foram secos em estufa a $37^{\circ} \mathrm{C}$. O extrato lipídico foi ressuspenso com $1 \mathrm{~mL}$ de isopropanol e procedeu-se da mesma forma utilizando "kit" enzimático para as análises do soro.

\section{Análises estatísticas}

Para a realização das análises estatísticas, foi utilizado o software SISVAR 4.0 (Ferreira, 2000). Utilizouse a análise de variância para as análises estatísticas dos resultados e o teste de Tukey para a comparação dos grupos, todos a $5 \%$ de probabilidade.

\section{RESULTADOS E DISCUSSÃO}

Os valores médios observados para o consumo de ração total e diário $(898,75 \mathrm{~g}$ e $15,51 \mathrm{~g})$ e ganho de peso total e diário $(200,97 \mathrm{~g}$ e $3,46 \mathrm{~g})$ dos tratamentos em estudo não apresentaram diferenças significativas $(\mathrm{p}>0,05)$. Apesar de alguns estudos relatarem um aumento da saciedade e redução do apetite, após o consumo de dietas ricas em fibras, os resultados do presente estudo não mostraram associação entre o consumo de fibras e redução da quantidade de ração ingerida. Silva et al. (2003), trabalhando com ratos wistar, durante 63 dias, para determinação do perfil lipídico e hepático, os quais foram alimentados com dietas, contendo $5 \%, 10 \%$ e $15 \%$ de farelo de aveia (fonte de fibra solúvel) e farelo de trigo (fonte de fibra insolúvel) não encontraram diferença significativa no consumo das dietas e no ganho de peso. Anderson et al. (1994), após realizarem um experimento com o objetivo de comparar os efeitos de diversas fontes de fibras sobre o perfil lipídico de ratos, não observaram diferenças significativas em relação ao consumo das dietas e ganho de peso dos ratos que receberam dietas suplementadas com farelo de trigo e farelo de aveia. Fernandes et al. (2002), também não observaram diferença significativa na quantidade ingerida de dietas com diferentes concentrações de fibras, por ratos machos, linhagem Wistar, recém-desmamados. No entanto, esses autores encontraram um ganho de peso médio significativamente menor nos grupos que ingeriram dietas com concentrações maiores de fibras. 


\section{Análises bioquímicas realizadas no soro sanguíneo dos} animais

Na Tabela 2, mostra-se a concentração média de colesterol total, HDL-c, LDL-c, VLDL-c e triacilglicerol (TAG) no soro de ratos, após 58 dias de consumo das dietas experimentais.

Conforme Tabela 2, ambas as fibras solúveis testadas (pectina e goma guar) foram eficientes em evitar o aumento do colesterol total e a LDL-c provocado pelo consumo de dieta hipercolesterolêmica $(p<0,05)$. Entretanto, não houve diferença significativa entre os tipos de fibras solúveis e a quantidade utilizada. A redução percentual média de colesterol observada entre os grupos que receberam dieta com fibras solúveis variou de $25,7 \%$ a $34,7 \%$ em relação ao grupo controle, consumindo a dieta $\mathrm{F}$ ( $5 \%$ celulose com $1 \%$ de colesterol). O percentual médio de redução da LDL-c variou entre $49,5 \%$ e $68,5 \%$. Observaram-se menores valores numéricos para o colesterol total e para LDL-c em animais que consumiram dietas contendo pectina a $10 \%$ e goma guar a $15 \%$.

Arjmandi et al. (1992), trabalhando com 96 ratos, durante 21 dias, para determinar a influência do consumo de fibras celulose, pectina, psyllium e farelo de aveia, todos a $10 \%$, sobre as frações lipídicas e hepáticas, verificaram que a fibra solúvel (pectina) reduziu em $21,67 \%$ os valores de colesterol total sérico, quando comparada com o grupo controle ( $10 \%$ de celulose com colesterol).

Anderson et al. (1994) estudaram o efeito de dez diferentes tipos de fibras sobre os níveis séricos e hepáticos de ratos alimentados com dietas contendo colesterol, durante três semanas, sendo a celulose a fibra controle. Ratos alimentados com fibras solúveis (psyllium, goma guar e pectina) tiveram significativa redução na concentração de colesterol total no soro e fígado.

Frias \& Sgarbieri (1998) realizaram um estudo com ratos wistar, durante 28 dias, para avaliar o efeito de dietas, contendo $0 \%, 10 \%$ e $15 \%$ de goma guar, sobre a concentração sérica de colesterol e de suas frações. Os autores observaram que a goma guar em concentrações igual ou superior a $10 \%$, foi eficaz no tratamento da hipercolesterolemia em ratos.

Fietz \& Salgado (1999) testaram o efeito da pectina e da celulose sobre os níveis séricos de colesterol e triacilgliceróis em ratos hiperlipidêmicos. Durante 30 dias, os animais foram alimentados com dietas, contendo $5 \%, 10 \%, 15 \%$ e $20 \%$ de pectina e celulose. As dietas com celulose foram as que produziram o menor efeito e, as com pectina, os efeitos foram mais significativos. As dietas com $10 \%$ e $15 \%$ de pectina apresentaram maior capacidade de reduzir os níveis de colesterol.

Os mecanismos de ação das fibras solúveis sobre o controle das frações lipídicas séricas ainda permanecem um tanto imprecisos, necessitando de maiores esclarecimentos. Entretanto, pesquisas mostram associação entre fibra solúvel e mudança da viscosidade do meio, aumentando a proteção da mucosa intestinal, interferindo na absorção de lipídios e sequestrando gorduras, mais especificamente colesterol, ácidos biliares, eliminando-os nas fezes (Rupérez \& Bravo, 2001).

Tabela 2 - Valores médios de colesterol total, HDL-c, LDL-c, VLDL-c e triacilglicerol do soro de ratos e respectivos coeficientes de variação (CV) conforme o tipo de dieta consumida durante 58 dias.

\begin{tabular}{cccccc}
\hline Dietas* & $\begin{array}{c}\text { Colesterol total } \\
(\mathrm{mg} / \mathrm{dL})\end{array}$ & $\begin{array}{c}\text { HDL-c } \\
(\mathrm{mg} / \mathrm{dL})\end{array}$ & LDL-c $(\mathrm{mg} / \mathrm{dL})$ & $\begin{array}{c}\text { VLDL-c } \\
(\mathrm{mg} / \mathrm{dL})\end{array}$ & $\begin{array}{c}\text { Triacilgliceróis } \\
(\mathrm{mg} / \mathrm{dL})\end{array}$ \\
\hline A & $76,37^{\mathrm{b}}$ & $40,73^{\mathrm{a}}$ & $20,40^{\mathrm{b}}$ & $15,23^{\mathrm{a}}$ & $68,63^{\mathrm{a}}$ \\
B & $88,48^{\mathrm{b}}$ & $42,18^{\mathrm{a}}$ & $32,72^{\mathrm{b}}$ & $13,58^{\mathrm{a}}$ & $67,91^{\mathrm{a}}$ \\
$\mathrm{C}$ & $86,84^{\mathrm{b}}$ & $44,22^{\mathrm{a}}$ & $31,38^{\mathrm{b}}$ & $11,23^{\mathrm{a}}$ & $56,18^{\mathrm{a}}$ \\
D & $77,04^{\mathrm{b}}$ & $36,65^{\mathrm{a}}$ & $28,74^{\mathrm{b}}$ & $11,65^{\mathrm{a}}$ & $58,25^{\mathrm{a}}$ \\
E & $84,59^{\mathrm{b}}$ & $38,93^{\mathrm{a}}$ & $33,08^{\mathrm{b}}$ & $12,57^{\mathrm{a}}$ & $62,87^{\mathrm{a}}$ \\
F & $116,95^{\mathrm{a}}$ & $38,28^{\mathrm{a}}$ & $64,77^{\mathrm{a}}$ & $13,89^{\mathrm{a}}$ & $69,46^{\mathrm{a}}$ \\
\hline CV & 11,14 & 21,27 & 23,01 & 38,35 & 39,99 \\
\hline
\end{tabular}

*Dietas: $\mathrm{A}=10 \%$ de pectina e $1 \%$ colesterol; $\mathrm{B}=15 \%$ de pectina e $1 \%$ colesterol; $\mathrm{C}=10 \%$ de goma guar e $1 \%$ colesterol; $\mathrm{D}=15 \%$ de goma guar e $1 \%$ de colesterol; $\mathrm{E}=$ controle com $5 \%$ celulose e sem colesterol; $\mathrm{F}=$ controle com 5\% de celulose e $1 \%$ colesterol. Médias nas colunas seguidas por letras iguais não diferem entre si ao nível de significância de 5\% pelo teste de Tukey. 
Os valores médios observados neste trabalho para o HDL-c, VLDL-c e TAG do soro de ratos, não diferiram significativamente $(p>0,05)$. Frias \& Sgarbieri (1998), observaram um aumento significativo nos níveis de HDLc de ratos alimentados com dietas com $10 \%$ e $15 \%$ de goma guar por 28 dias. Silva et al. (2003), verificaram aumento significativo nos soros de ratos alimentados com dietas suplementadas com farelo de aveia. Porém, o mesmo efeito não foi observado para ratos alimentados com dieta suplementadas com farelo de trigo. Os autores ainda verificaram uma redução significativa nos níveis de VLDL-c e TAG dos ratos alimentados com dietas contendo $15 \%$ de farelo aveia e $15 \%$ de farelo de trigo.

Fietz \& Salgado (1999), observaram uma redução significativa nos níveis séricos de TAG de ratos submetidos a dietas com $10 \%$ e $15 \%$ de celulose ou pectina. As fibras solúveis podem agir diminuindo a absorção intestinal de triacilgliceróis, provocando pequeno aumento na quantidade de gordura fecal e contribuindo para reduzir os níveis de triacilgliceróis séricos (Costa et al., 1997).

Por outro lado, parece que as fibras insolúveis, por diminuírem o tempo de trânsito intestinal, diminuem a absorção de gorduras, podendo diminuir os níveis de triacilgliceróis séricos (Raupp, 1996).

O aumento do LDL-c no soro constitui o principal fator de risco para as doenças cardiovasculares. Portando, a redução do LDL-c é fundamental para a prevenção das doenças cardiovasculares (Brown et al., 1999). O aumento do consumo de produtos alimentícios industrializados, a base de cereais refinados e alimentos de origem animal, constituem o padrão alimentar pobre em fibras alimentares observado nos países ocidentais (Wu et al., 2003; Lairon et al., 2005). É necessário repensar essa situação uma vez que esse padrão alimentar está fortemente associado com o aumento das doenças cardiovasculares.

\section{Análises químicas e bioquímicas no fígado dos animais experimentais}

Na Tabela 3, apresentam -se os valores médios de colesterol total, triacilgliceróis, lipídios totais e peso do fígado de ratos alimentados com diferentes dietas durante 58 dias.

Ambas as fibras solúveis testadas (pectina e goma guar), quando ingeridas pelos animais, foram eficientes em evitar o aumento do colesterol total e lipídeos totais dos fígados dos ratos que consumiram dieta hipercolesterolêmica $(p<0,05)$ (Tabela 3). A dieta com $10 \%$ de pectina mostrou-se menos eficiente que as demais para prevenir o aumento dos lipídeos totais. Quanto aos valores de TAG do fígado dos animais, verificou-se uma tendência a redução de seus níveis com o uso das fibras, mas não foi observada diferença significativa entre os ratos que receberam dietas hipercolesterolêmicas com fibras solúveis em relação ao grupo controle $(p>0,05)$. Os valores médios observados neste trabalho para o peso do fígado de ratos apresentados na Tabela 3 não apresentaram diferença significativa.

Anderson et al. (1994) verificaram uma diminuição no peso relativo do fígado de ratos alimentados com goma guar e pysillium em relação aos ratos alimentados com celulose. Gallaher et al. (2000) verificaram que ratos alimentados com dietas, contendo $10 \%$ de glucomanana, citosana e glucomanana + citosana, diminuiram o peso do fígado em relação ao grupo controle com $10 \%$ de celulose.

Tabela 3 - Valores médios de colesterol total, triacilgliceróis, lipídios totais e peso do fígado de ratos e respectivos coeficientes de variação (CV) de ratos alimentados com diferentes dietas durante 58 dias.

\begin{tabular}{ccccc}
\hline Dietas* $^{*}$ & $\begin{array}{c}\text { Colesterol total } \\
(\mathrm{mg} / \mathrm{g})\end{array}$ & $\begin{array}{c}\text { Triacilgliceróis } \\
(\mathrm{mg} / \mathrm{g})\end{array}$ & $\begin{array}{c}\text { Lipídios totais } \\
(\mathrm{g} / 100 \mathrm{~g})\end{array}$ & $\begin{array}{c}\text { peso do fígado } \\
(\mathrm{g})\end{array}$ \\
\hline $\mathrm{A}$ & $20,52^{\mathrm{b}}$ & $58,99^{\mathrm{ab}}$ & $22,05^{\mathrm{b}}$ & $10,12^{\mathrm{a}}$ \\
$\mathrm{B}$ & $17,39^{\mathrm{b}}$ & $55,38^{\mathrm{ab}}$ & $16,55^{\mathrm{bc}}$ & $8,57^{\mathrm{a}}$ \\
$\mathrm{C}$ & $18,85^{\mathrm{b}}$ & $54,28^{\mathrm{ab}}$ & $16,60^{\mathrm{bc}}$ & $7,63^{\mathrm{a}}$ \\
$\mathrm{D}$ & $16,09^{\mathrm{b}}$ & $54,44^{\mathrm{ab}}$ & $15,85^{\mathrm{bc}}$ & $9,68^{\mathrm{a}}$ \\
E & $17,43^{\mathrm{b}}$ & $51,28^{\mathrm{b}}$ & $13,25^{\mathrm{c}}$ & $9,05^{\mathrm{a}}$ \\
F & $39,31^{\mathrm{a}}$ & $86,96^{\mathrm{a}}$ & $35,02^{\mathrm{a}}$ & $10,95^{\mathrm{a}}$ \\
\hline CV & 24,27 & 24,22 & 15,07 & 15,86 \\
\hline
\end{tabular}

*Dietas: A $=10 \%$ de pectina e $1 \%$ colesterol; $\mathrm{B}=15 \%$ de pectina e $1 \%$ colesterol; $\mathrm{C}=10 \%$ de goma guar e $1 \%$ colesterol; $\mathrm{D}=15 \%$ de goma guar e $1 \%$ de colesterol; $\mathrm{E}=$ controle com 5\% celulose e sem colesterol; $\mathrm{F}=$ controle com 5\% de celulose e $1 \%$ colesterol. Médias nas colunas seguidas por letras iguais não diferem entre si ao nível de 5\% de significância pelo teste de Tukey. 


\section{CONCLUSÕES}

As fibras solúveis pectina e goma guar consumidas nas concentrações de 10 e $15 \%$ foram eficazes na redução dos níveis do colesterol total e LDL-c no soro, bem como do colesterol total e lipídeos totais no fígado, porém a ingestão das fibras solúveis não alterou significativamente os níveis de HDL-c, VLDL-c e TAG no soro dos ratos.

Ambas as fibras solúveis estudadas, pectina e goma guar, apresentaram, quando consumidas, efeitos semelhantes quanto às frações lipídicas estudadas.

\section{REFERÊNCIAS BIBLIOGRÁFICAS}

ALLAIN, C.C.; POON, L.S.; CHAN, C.S.; RICHMOND, W.; FU, P.C. Enzimatic determination of total serum cholesterol. Clinical Chemical, Washington, v.20, n.4, p.470-475, 1974.

ANDERSON, J.W.; JONES, A.E.; RIDDEL-MASON, S. Tem different dietary fibers have significantly different effects on serum and liver lipids of cholesterol-fed rats. Journal of Nutrition, Baltimore, v.124, n.1, p.78-83, Jan. 1994.

ARJMANDI, B.H.; CRAIG, J.; NATHANI, S.; REEVES, R.D. Soluble dietary fiber and cholesterol influence in vivo hepatic and intestinal cholesterol biosyntesis in rats. Journal of Nutrition, Baltimore, v.122, n.7, p.15591565, July 1992.

\section{ASSOCIATION OF ANALYTICAL CHEMISTS. Official} methods of analysis. 14.ed. Washington, DC, 1990.

BELL, L.P.; HECTORN, K.J.; REYNOLDS, H.; HUNNINGHAKE, D.B. Cholesterollowering effects of soluble-fiber cereals as part of a prudent diet for patients with mild to moderate hypercholesterolemia. American Journal of Clinical Nutrition, New York, v.52, p.10201026, 1990.

BROWN, L.; ROSNER, B.; WILLETT, W.W.; SACKS, F.M. Cholesterol-lowering effects of dietary fiber: a metaanalysis. American Journal of Clinical Nutrition, New York, v.30, n.69, p.30-42, 1999.

BUCKERIDGE, M.S.; TINÉ, M.A. Composicão polissacarídica: estrutura da parede celular e fibra alimentar. In: ___ Fibra dietética in Iberoamérica: tecnologia y salud. São Paulo: Sarvier, 2001. p.27-38.
CARA, L.; DUBOIS, C.; BORE, P.; ARMAND, M.; SENFI, M.; PORTUGAL, H.; PAUI, A.M.; BERNARD, P.M.; LAIRON, D. Effects of oat bran, rice bran, wheat fiber, and wheat germ on postprandial lipemia in healthy adults. American Journal of Clinical Nutrition, New York, v.55, p.81-88, 1992.

CONSELHO FEDERAL DE MEDICINA VETERINÁRIA. Resoluçããon 714, de 20 de junho de 2002. Disponível em: 〈http://WwW.cfmv.org.br/portal/legislacao/l 'resolucoes/resolucao 714.pdf.y. Acesso em: 29 out. 2008 .

COSTA, R.P.; SILVA, C.C.; MAGNONI, C.D. Importância das fibras na prevenção de doenças cardiovasculares.

Revista Brasileira de Nutrição Clínica, São Paulo, v.12, p.151-154, 1997.

EASTWOOD, M.A. The fisiological effect of dietary fiber: on uptake. Annual Review of Nutrition, Palo Alto, v.12, p.19-36, 1992.

FERNANDEZ, S.A.V.; TANNURI, U.; DOMIGUES, G.; UEHARA, D.Y.; CARRAZZA, F.R. Efeito de dietas ricas em fibras sobre ratos em crescimento: estudo experimental. Pediatria, São Paulo, v.24, n.2, p.32-37, 2002.

FERREIRA, D.F. Análises estatísticas por meio do Sisvar para Windows versão 4.0. In: REUNIÃO ANUAL DA REGIÃO BRASILEIRA DA SOCIEDADE

INTERNACIONAL DE BIOMETRIA, 45., 2000, São Carlos. Anais... São Carlos: UFSCar, 2000. p.255-258.

FIETZ, V.R.; SALGADO, J.M. Efeito da pectina e da celulose nos níveis séricos de colesterol e triglicerídeos em ratos hiperlipidemicos. Ciência e Tecnologia de Alimentos, Campinas, v.19, n.3, p.318-321, set./dez. 1999.

FOLCH, J.; LESS, M.; SLOANE-STANLEY, G.H.A. Simple method for isolation and purification of total lipids from animals tissues. Journal of Biological Chemistry, Bethesda, v.226, n.1, p.407-411, May 1957.

FOSSETI, P.; PRENCIPE, L. Serum triglycerides determined calçorimetrially with enzime theat produces hyddrogen peroxidase. Clinical Chemistry, Washington, v.28, n.10, p.2077-2080, Oct. 1982. 
FRIAS, A.C.D.; SGARBIERI, V.C. Guar gum effects on food intake, blood serum lipids and glucose levels of Wistar rats. Plant Foods for Human Nutrition, Dordrecht, v.48, p.1-14, 1998.

FRIEDEWALD, W.T.; LEVY, R.I.; FREDRICKSON, D.S. Estimation of the concentration of low density lipoprotein cholesterol in plasma, without use of preparative ultracentrifuge. Clinical Chemistry, Baltimore, v.18, n.6, p.499-502, June 1972.

GALLAHER, C.M.; MUNION, J.H.; WISE, J. Cholesterol reduction by glucomanana and chitosan is mediated by changes in cholesterol absorption asnd bile acid and fat excretion in rats. Minnesota: American Society for Nutritional Sciences, 2000. 2559p.

JUDD, P.A.; TRUSWELL, A.S. Comparasion of the effects of hight and low metthoxyl pectin on blood and faecal lipids in man. British Journal of Nutrition, London, v.48, n.3, p.451-458, Nov. 1982.

KRIS-ETHERTON, P.M.; KRUMMEL, D.; RUSSELL, M.E. The effect of diet on plasma lipids, lipoproteins, and coronary heart disease. Journal of American Dietetic Association, New York, v.88, p.1373-400, 1988.

LAIRON, D.; ARNAULT, N.; BERTRAIS, S.; PLANELLS, R.; CLERO, E.; HERCBERG, S.; BOUTRON-RUAULT, M.C. Dietary fiber intake and risk factors for cardiovascular disease in French adults. American Journal of Clinical Nutrition, New York, v.82, p.1185-94, 2005.

LONDERO, P. M. G.; RIBEIRO, N. D.; CARGNELUTTI FILHO, A. Teores de fibra e rendimento de grãos em populações de feijão. Ciência e Agrotecnologia, Lavras, v.32, n.1, p.167-173, jan./fev., 2008.

MATTOS, L.L. de; MARTINS, I.S. Consumo de fibras alimentares em população adulta. Revista de Saúde Pública, São Paulo, v.34, n.1, p.50-55, fev. 2000.
MELO, D. S. de; CORRÊA, A. D.; MARCOS, F. C. A.; SOUSA, R. V. de; ABREU, C. M. P. de; SANTOS, C. D. dos. Efeitos da farinha de folhas de mandioca sobre a peroxidação lipídica, o perfil lipídico sangüineo e o peso do fígado de ratos. Ciência e Agrotecnologia, Lavras, v.31, n.2, p.420-428, mar./abr., 2007.

POTTY, V.H. Physico-chemical aspects, physiological functions, nutritional importance and technological significance of dietary fibers: a critical appraisal. Journal Food Science Technology, Mysore, v.33, n.1, p.1-18, Jan./ Feb. 1996.

RAUPP, D.S.; SGARBIERI, V.C. Efeito de frações fibrosas extraídas de feijão (Phaseolus vulgaris, L.) na utilização de macro e micronutrientes da dieta pelo rato. Ciência e Tecnologia de Alimentos, Campinas, v.16, n.2, p.100-107, jul./set. 1996.

RUPÉREZ, P.; BRAVO, L. Oligofructanos e gomas. In:

Fibra dietética in Iberoamérica: tecnologia y salud. São Paulo: Sarvier, 2001. p.61-75.

SILVA, M.A.M.; BARCELOS, M.F.P.; SOUSA, R.V.; LIMA, H.M.; FALCO, I.R.; LIMA, A.L.; PEREIRA, M.C.A. Efeito das fibras dos farelos de trigo e aveia sobre o perfil lipídico no sangue de ratos (Rattus Norvegicus) Wistar. Ciência e Agrotecnologia, Lavras, v.27, n.6, p.1321-1329, nov./dez. 2003.

WEICKERT, M.O.; PFEIFFER, A.F.H. Metabolic effects of dietary fiber consumption and prevention of diabetes. The Journal of Nutrition, Bethesda, v.138, p.439-442, 2008.

WU, H.; DWYER, K.M.; FAN, Z.; SHIRCORE, A.; FAN, J.; DWYER, J.H. Dietary fiber and progression of atherosclerosis: the Los Angeles Atherosclerosis Study. American Journal of Clinical Nutrition, New York, v.78, p.1085-1091, 2003. 